\title{
Evidence of mineral dust altering cloud microphysics and precipitation
}

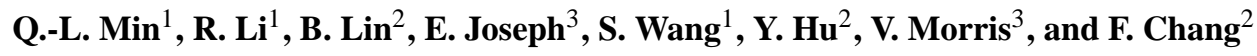 \\ ${ }^{1}$ Atmospheric Sciences Research Center, State University of New York, USA \\ ${ }^{2}$ Science Directorate, NASA Langley Research Center, USA \\ ${ }^{3}$ NOAA Center for Atmospheric Sciences, Howard University, USA
}

Received: 2 June 2008 - Published in Atmos. Chem. Phys. Discuss.: 3 November 2008

Revised: 5 May 2009 - Accepted: 11 May 2009 - Published: 18 May 2009

\begin{abstract}
Multi-platform and multi-sensor observations are employed to investigate the impact of mineral dust on cloud microphysical and precipitation processes in mesoscale convective systems. For a given convective strength, small hydrometeors were more prevalent in the stratiform rain regions with dust than in those regions that were dust free. Evidence of abundant cloud ice particles in the dust sector, particularly at altitudes where heterogeneous nucleation of mineral dust prevails, further supports the observed changes of precipitation. The consequences of the microphysical effects of the dust aerosols were to shift the precipitation size spectrum from heavy precipitation to light precipitation and ultimately suppressing precipitation.
\end{abstract}

\section{Introduction}

Among all recognized climate forcing mechanisms, aerosol indirect effects are currently the greatest source of uncertainty in model forecasts of climate change. In recent years vigorous research has ensued focusing on key unanswered questions that persist due to limited laboratory and field observations of aerosol-cloud-precipitation interactions. As one of the four major terrestrial sources of atmospheric aerosols (desert dust, biomass burning, biogenic and anthropogenic air pollution), mineral dust is responsible for significant climate forcing through direct effect on solar and thermal radiation as well as indirect effect on clouds and precipitation processes. Measurements from CRYSTAL-FACE (The Cirrus Regional Study of Tropical Anvils and Cirrus Layers - Florida Area Cirrus Experiment) for example provided clues to the presence of extremely high numbers of het-

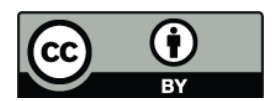

Correspondence to: Q.-L. Min (min@asrc.cestm.albany.edu) erogeneous ice nuclei within clouds that formed in residual air masses from the Saharan air layer (DeMott et al., 2003; Sassen et al., 2003). Some observations suggest that mineral dusts and air pollution may suppress surface precipitation in warm and topographic rains due to changes in cloud condensation nuclei (CCN) concentration (Andreae et al., 2004; Rosenfeld et al., 2001). And modeling studies predict that dusts as giant CCN may enhance collision and coalescence during droplet growth and therefore increase warm precipitation and decrease cloud albedo (Teller and Levin, 2006; van den Heever et al., 2006). However, aerosol indirect effects on deep convection cloud system are poorly understood. To better discern the effects of dust on cloud microphysical processes more assessment is needed of cases where the effects of thermodynamics and dynamics are carefully considered.

Microphysical processes associated with dust-cloud interaction also affect cloud hydrometeor profiles and phase changes, which in turn alter the cloud dynamics and thermodynamics through latent heat release. The vertical precipitation profiles reflect the combined effects of dynamic, thermodynamic, and microphysical processes in cloud systems. Few, if any, studies have reported observed evidence of the impacts of mineral dust on rainfall internal structures, particularly in deep convective rains. In this paper, we utilize multiple sensors on multiple observing platforms to investigate the mineral dust impact on cloud and precipitation over the Atlantic Ocean.

\section{Data analysis}

A trans-Atlantic dust outbreak of Saharan origin occurring 1-7 March 2004 (Morris et al., 2006) was considered in this study. Mineral dust associated with this outbreak interacted with cloud systems as the dust layer traveled across the tropical eastern Atlantic Ocean. A comprehensive set of

Published by Copernicus Publications on behalf of the European Geosciences Union. 


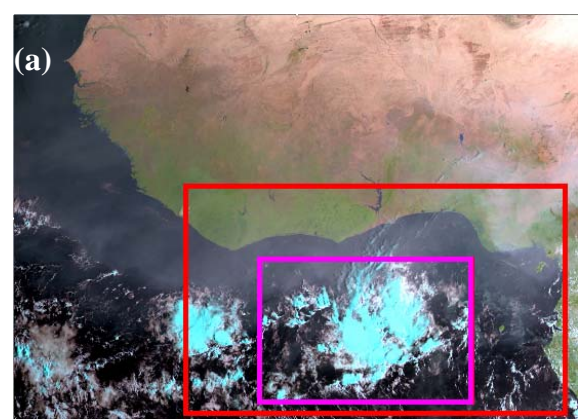

(c)

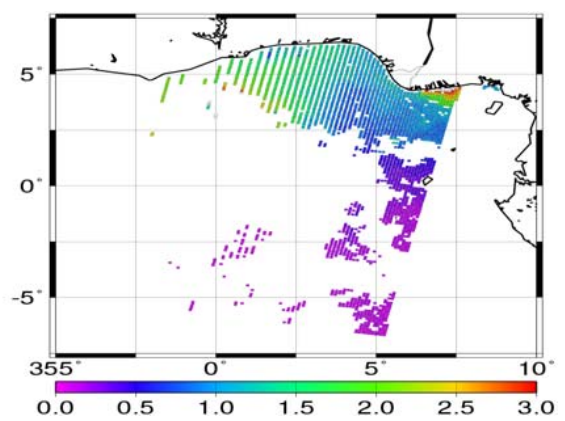

(e)

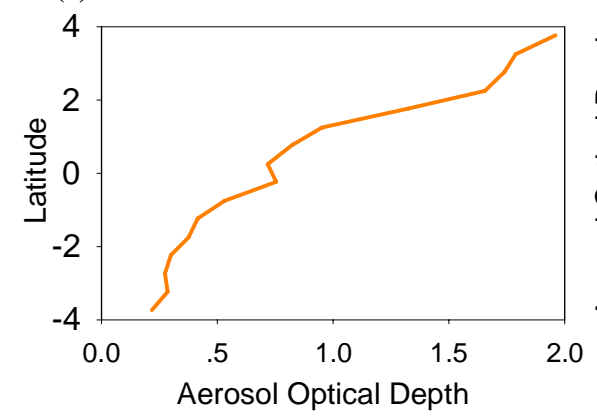

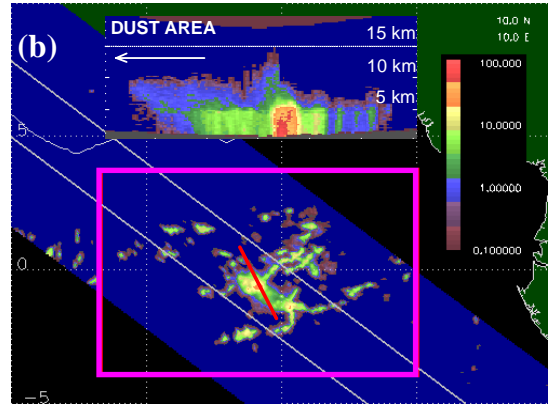

(d)

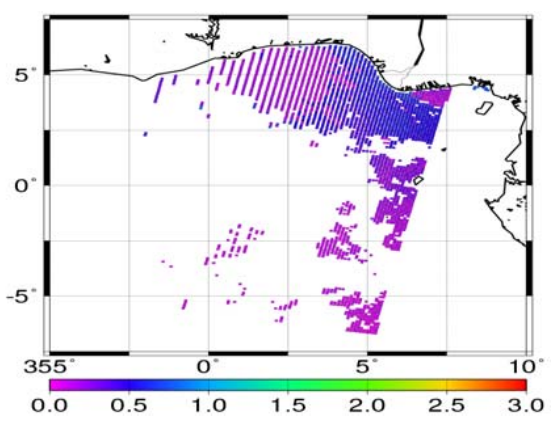

(f)

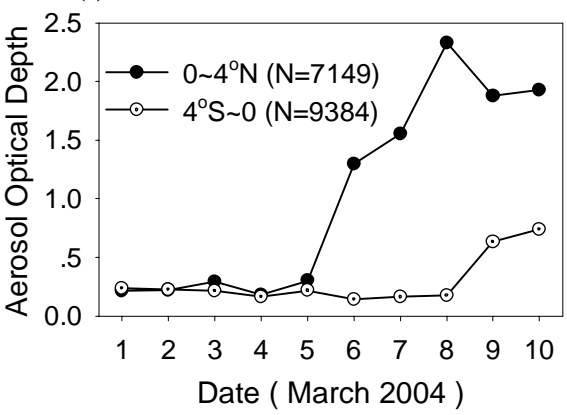

Fig. 1. (a) Meteosat-8 RGB composite visible image at 09:12 UTC on 8 March, 2004 (The above information has been supplied by EUMETSAT 2007); (b) TMI precipitation image on orbital 35979 at 09:11 UTC and the vertical cross section (along the red line) derived from PR data (swath indicated by the two gray lines); (c) column aerosol optical depth (AOD) in coarse mode retrieved from MODIS at 09:55 UTC (d) same as (c), but in fine mode (e) Zonal averaged column aerosol optical depth retrieved from MODIS at 09:55 UTC in the study domain (magenta box); (d) Time series of area mean aerosol optical depth retrieved from MODIS in the south and north sectors during 1 to 10 March 2004.

thermodynamic, dynamic, and cloud microphysical observations of the dust layer and precipitation systems it encountered was gathered by several satellites, including TRMM, Terra and Aqua, and Meteosat- 8 , and by surface-based measurements. We selected a special case on 8 March 2004, as illustrated by the Meteosat- 8 RGB composite image at 09:12 UTC (Fig. 1a). The image reveals a well developed mesoscale convective system (MCS, shown in blue and white colors) that is partially within the dust layer on the northern boundary and more pristine marine air on its southern sector. As indicated by the series of Meteosat- 8 composite images (http://www.atmos-chem-phys.net/9/3223/2009/ acp-9-3223-2009-supplement.zip), this dust plume originated from the Sahara Desert and transported into the At- lantic Ocean. The MCS intersected the dust storm as the MCS moved north-west and the dust storm spread southward towards the equator. This MCS was in its mature stage and it lasted for a long time. Figure $1 \mathrm{~b}$ shows the spatial pattern of precipitation with several strong convection cores and their associated wider spread stratiform clouds, derived from the measurement of the TRMM Microwave Imager (TMI) at 09:11 UTC. The two parallel lines indicate the swath of the TRMM Precipitation Radar (PR). The vertical cross section of PR reflectivity along the red line (Fig. 1b) indicates that the rain top of this deep convective rainfall reached altitudes of about $14 \mathrm{~km}$. At 09:55 UTC, sensors on Terra also detected the interaction of this dust layer with the clouds. In the vicinity of the cloud system, MODIS 
retrieved aerosol optical depths (AOD) at $550 \mathrm{~nm}$ were much greater in the coarse mode (Fig. 1c) than in the fine mode (Fig. 1d), and changes in the fine mode from $2^{\circ} \mathrm{N}$ to $4^{\circ} \mathrm{S}$, where the MCS was located, were very small. MODIS observation on 9 March, 2004 with more retrievals of AOD at the MCS location also provided a consistent assessment (not shown here). This indicates that although there were some hot spots along the dust storm track, aerosols were dominant with mineral dust. Additionally, this event was indentified as a typical "dust" event by the NASA MODIS Rapid Response Project ${ }^{1}$, the NOAA Operational Significant Event Imagery team (OSEI) ${ }^{2,3}$, and Nalli et al. (2005) and Morris et al. (2006) based on observations from the trans-Atlantic Aerosol and Ocean Science Expeditions (AEROSE) experiment. Both NASA MODIS Rapid Response and NOAA OSEI teams did not announce significant fires at that time in the region.

The zonal averaged AOD clearly decreased from $4^{\circ} \mathrm{N}$ to $1^{\circ} \mathrm{S}$ and remained almost constant in the area further south (Fig. 1e). We mainly focused on the region from $4^{\circ} \mathrm{S}$ to $4^{\circ} \mathrm{N}$, and $10^{\circ} \mathrm{W}$ to $5^{\circ} \mathrm{E}$ (magenta box, Fig. 1), and segregated data from $4^{\circ} \mathrm{N}$ to $0.5^{\circ} \mathrm{S}$ as the dust sector and from $1^{\circ} \mathrm{S}$ and $4^{\circ} \mathrm{S}$ as the dust-free sector. Time series of area mean AOD in the dust and dust-free sectors shown in Fig. 1 illustrate that the gradient of dust loading had persisted for a few days.

Investigating the vertical structure of precipitation is crucial for understanding dynamic and microphysical processes in cloud systems. The PR provides profile measurements of precipitation-sized hydrometeors at $4.3 \mathrm{~km}$ horizontal and $250 \mathrm{~m}$ vertical resolutions at nadir. We used the PR attenuation-corrected reflectivity (product 2A25, Iguchi et al., 2000) to investigate the evolution of precipitation-sized hydrometeors under both dust and dust-free conditions. This reflectivity represents the combined effect of hydrometeor effective size and total amount.

To minimize the impacts of cloud evolution stages, we picked this unique case of a mature MCS, in which a portion of the MCS was under the influence of mineral dust. Although there were some internal variations, this case is better constrained than separated MCSs in different time and location. Each convection cell in MCSs also goes through a life cycle, including a formative stage, intensifying stage, mature stage and decaying stage. In the TRMM PR 2A25 product, young, active and violent convection-related rains are identified as convective rains based on its very strong radar reflectivity, which is related to more and/or large particles requiring strong updraft velocity to lift them (Steiner et al., 1995; Awaka et al., 1997; Houze, 1997). While older, inactive

\footnotetext{
${ }^{1}$ http://rapidfire.sci.gsfc.nasa.gov/gallery/?2004068-0308/Dust. A2004068.1430.8km.jpg; MODIS observation

${ }^{2} \mathrm{http}$ ///www.osei.noaa.gov/Events/Dust/Africa_W/2004/ DSTafr067_G12.jpg; GOSE observation

${ }^{3}$ http://www.osei.noaa.gov/Events/Dust/Africa_W/2004/ DSTafr068_N7.jpg; NOAA 17 observation
}

and weak convection-related rains are identified as stratiform rains based on their weak radar reflectivity and the feature of radar bright band, which indicate weak updraft velocity and vertical mixing. The separation of stratiform and convective rains itself constrains the variations due to different evolution. Also, the stratiform rain rate is largely determined by the updraft intensity of its related convection core (Gamache and Houze, 1983). The relative intensity of stratiform rain to convective rain is less dependent on the updraft intensity and evolution stage. In this study, therefore, we separated PR measurements of the observed cloud system into convective and stratiform rain regions, and study the microphysical and dynamic differences and the relationship between these two rain regimes under the influence of mineral dust.

Figure 2 shows Contoured Frequency by Altitude Diagrams (CFADs, Yuter and Houze, 1995) of PR reflectivity for both convective and stratiform precipitation regions in the dust and dust-free sectors. The attributes of the reflectivity distribution in the convective region (broadly distributed with higher values at all altitudes) suggest the presence of relatively large and/or more ice particles that have grown and aggregated in strong convection. In contrast, the reflectivity of the stratiform clouds in both the dust and dust-free sectors is more narrowly distributed particularly above the freezing level; the mode of the reflectivity frequency occurs at a much lower value, consistent with the dominance of vapor deposition as the primary means of particle growth (Houze, 1997).

Microphysical processes are directly impacted by convection strength as strong convection lifts large hydrometeors through the freezing level and supports large graupel above that level. Following other researchers (Zipser and Lutz, 1994) we used the vertical slope of the maximum reflectivity (VSMR) to evaluate convective updrafts and assess the strength of convection between the dust and dust-free sectors of the convective region. The VSMR in the middle and upper troposphere were $4.14 \pm 0.16(\mathrm{dBZ} / \mathrm{km})$ in the dust sector and $3.74 \pm 0.15(\mathrm{dBZ} / \mathrm{km})$ in the dust-free sector, respectively, indicating slightly stronger convection in the latter sector. Above $8 \mathrm{~km}$ the PR detected higher reflectivity in the dust-free sector of the convective region than in the dust sector. In contrast, over the stratiform regions, much more and/or large precipitating hydrometeors were found in the dust sector than in the dust-free sector (more discussion later), as illustrated by PR reflectivity in Fig. 2. This analysis reveals a substantial difference of hydrometeors in the convective and stratiform regions and the contrast between dusty and dust-free clouds.

Since dynamics are the leading factor in determining the development of mesoscale convective systems, differences in cloud dynamics rather than mineral dust could be the dominant cause of the contrasting microphysics described above for both the stratiform and convective regions. In order to differentiate the impact of dynamics on hydrometeor growth and precipitation, we conducted two sensitivity experiments on the dynamics: one at the mesoscale and 

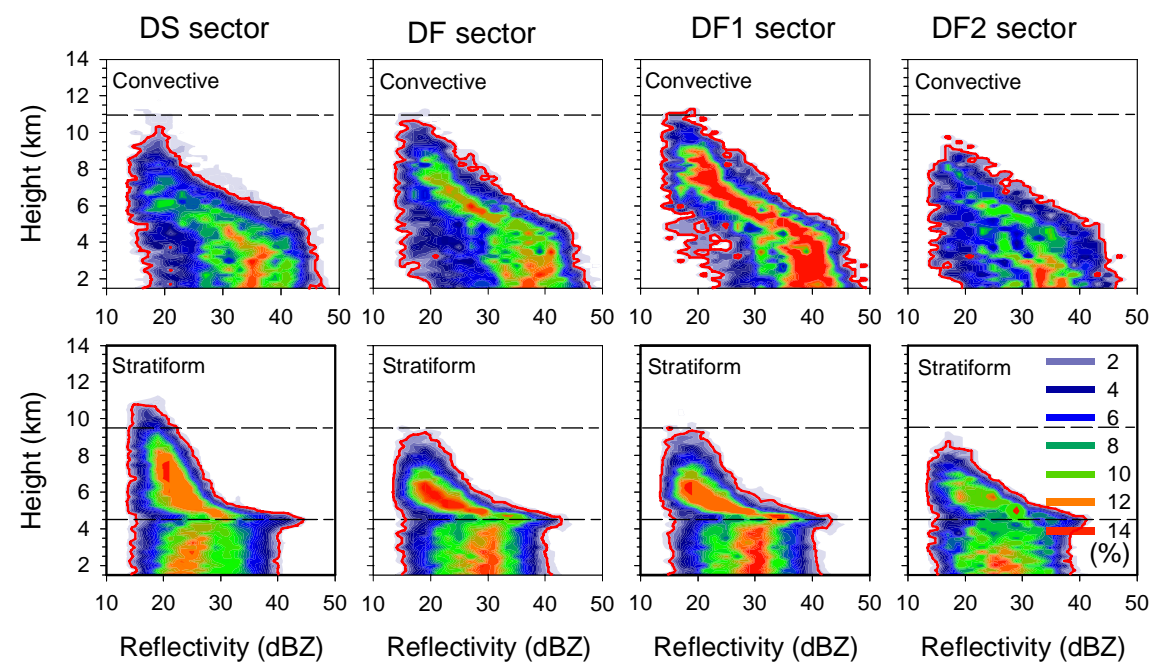

Fig. 2. Contoured frequency by altitude diagrams (CFADs) of PR attenuation corrected reflectivity for both convective and stratiform precipitation regions for both dusty (DS) and dust-free sectors and for divided sub-sectors (DF1 and DF2) in dust-free sector.

the other at the convective scale. First, we further divided the dust-free region into two sub-sectors along $1.5^{\circ} \mathrm{S}$ : one near the rain band center with relatively strong updraft $(\mathrm{DF} 1, \mathrm{VSMR}=3.72 \pm 0.14(\mathrm{dBZ} / \mathrm{km}))$ and the other at the trailing edge with weak updraft (DF2, VSMR $=5.03 \pm 0.17$ $(\mathrm{dBZ} / \mathrm{km}))$. As aerosol loading observed by MODIS is generally uniform in the dust-free sector, observed differences are isolated to variations in convective strengths. It is clear that stronger convection is also associated with higher reflective startiform rain tops when the DF1 sub-sector is compared with the DF2 sub-sector because stronger convection can lift and support larger hydrometeors at higher altitudes and provide stronger outflows for anvil development. Without dust as an additional source of ice nuclei, this convection-stratiform consistency is commonly found in convective cloud systems (Houze, 1997). Because the convection observed in the dust sector is slightly weaker than that in the dust-free sector while their associated stratiform rain above $8 \mathrm{~km}$ are stronger, this analysis suggests that convection strength may not be the dominant cause of the hydrometeor differences observed between dust and dust-free sectors. The dry environment that is characteristic of SAL (Sahara Air Layer) is another possible cause of the hydrometeor difference. Dry air, however, should reduce the water vapor supply to the system and suppress convection, resulting in limited growth of precipitating hydrometeors in both convective and stratiform regions. Therefore, alteration of the cloud microphysics by mineral dust could be a plausible explanation for the observed increase in hydrometeors over dusty stratiform regions.

Second, we segregated each convective cell and studied the relationship of stratiform rain with its associated convective rain in the convective core in both dust and dust-free sectors (Fig. 3a). Classification of each convective cell as a dust cell or a dust-free cell depends on its geolocation with respect to the dust loading. Due to a limited cell number in this MCS, we included four more cells that were partially within the buffer zone into our analysis. Since a substantial portion of convective rain pixels of DF1 was inside the dustfree sector, we classified it as a dust-free cell. If we remove DF1 from our statistics, the relationship between stratiform and convective rains in the dust-free sector will not change. Due to limited pixels in each convective core, the standard VSMR approach for convection strength is not applicable. We used the maximum reflectivity, mean reflectivity, and mean rain rate at $8 \mathrm{~km}$ in the convective core as indicators for the strength of convective updrafts. These indicators are similar to those used by Nesbitt et al. (2000) and Zipser et al. (2006): the maximum radar reflectivity at $6 \mathrm{~km}$ and the maximum height of radar echo ( 30 or $40 \mathrm{dBz}$ ).

As shown in Fig. 3b-d, the mean reflectivity and mean rain rate in the corresponding stratiform rain exhibit distinct behavior between the dust and dust-free sectors as a function of convection strength. Based on Gamache and Houze (1983), the stratiform rain rate is largely determined by the updraft intensity of its related convective core. Relatively stronger stratiform rain should be associated with relatively stronger convective rain. The relative intensity of stratiform rain to convective rain is weakly dependent on the updraft intensity and evolution stage. In the dust-free sector where the aerosol loading was relatively uniform, a tighter relationship between the mean reflectivity (and rain rate) of stratiform vs. convective rains is clearly evident. Indeed there were still some differences of evolution stage among those individual cells in this MCS. Some cells can be relatively younger/older than others. Variation of evolution stage of convective cells may result in some variations in Fig. 3b$\mathrm{d}$ under both dust and dust-free conditions. However, the 


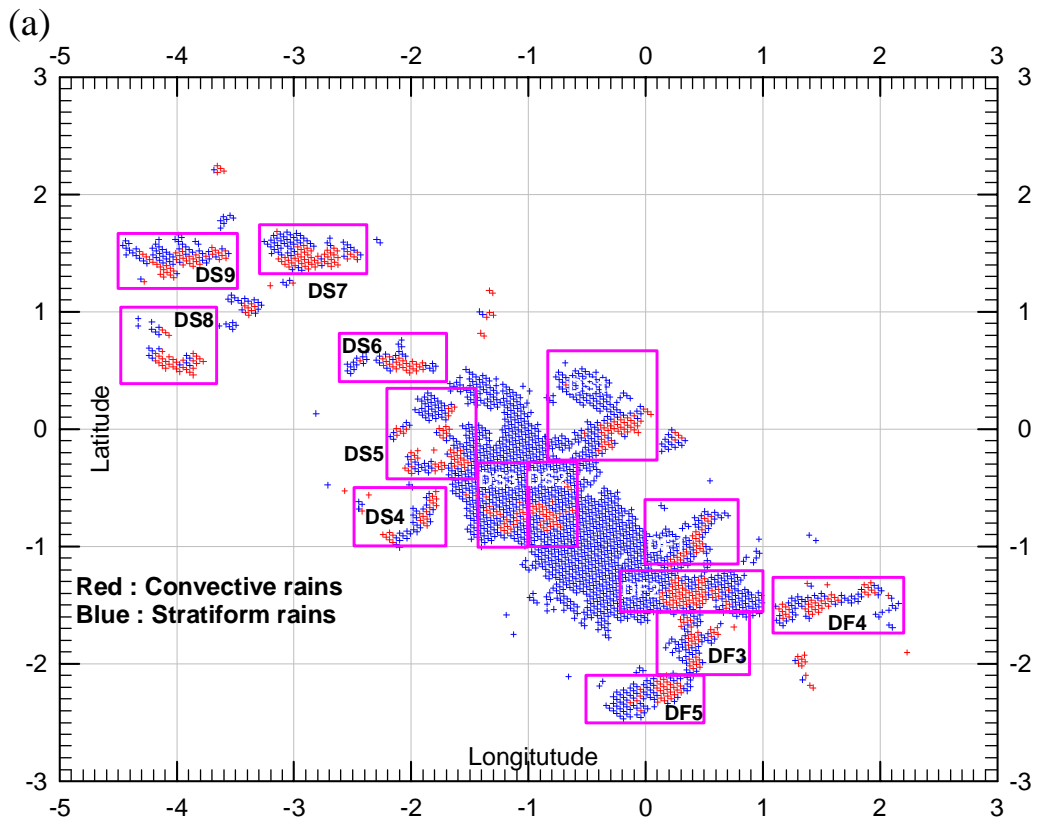

(b)

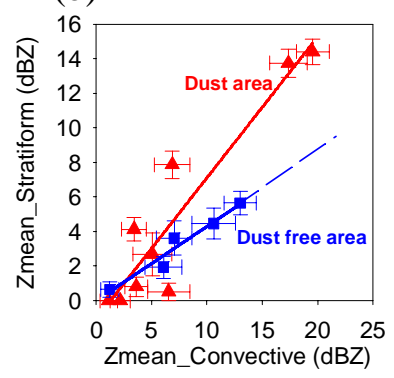

(c)

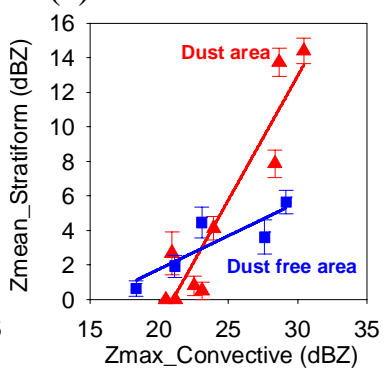

(d)

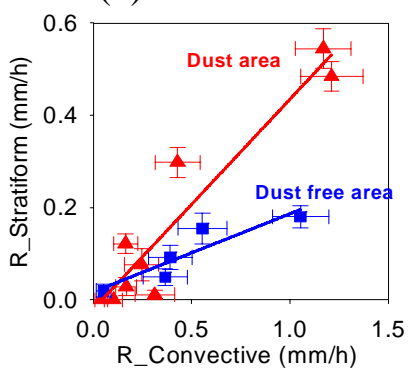

Fig. 3. TRMM PR observed (a) Distribution of selected stratiform rains and their associated convection cells in dust (DS1 to DS9) and dust free condition (DF1 to DF5). The relationship between the stratiform rain against the convective rains at $8 \mathrm{~km}$ altitude are indicated by (b) mean reflectivity vs mean reflectivity, (c) mean reflectivity vs. maximum reflectivity, and (d) mean rain rate vs mean rain rate (Red for dust, blue for dust-free).

variation of the relative intensity of stratiform rain to convective rain in the dust sector is smaller than the difference of the relative intensity between the dust and dust-free sectors. It suggests that the variation associated with possible different evolution stages is smaller than the difference between the dust and dust-free conditions. Therefore, qualitatively, we could speculate that for a given convection strength, there was relatively stronger rain at altitudes above $8 \mathrm{~km}$ in the stratiform rain region of dust-polluted areas than those in its dust-free counterpart. Hence, observed enhancement of precipitation in the upper stratiform region in the dust sector may be mainly due to the microphysical effects of the mineral dust-cloud-precipitation interaction and to a lesser extent due to dynamic and thermodynamic effects.
Further understanding the microphysical effects of mineral dust on precipitation requires information of hydrometeor size distribution. However, the single wavelength radar system of the PR limits its capability to distinguish the sizes of precipitating particles. As the scattering of upwelling microwave radiation is primarily due to precipitation-sized ice hydrometeors present above the emitting rain layer and strongly depends on hydrometeor sizes (Lin and Rossow, 1997; Vivekanandan et al., 1990; Wilheit et al., 1982), it is possible to infer hydrometeor size information from passive microwave remote sensing sensors such as TMI. While $37 \mathrm{GHz}$ ice scattering is attributed to the presence of larger (millimeter) graupel or frozen raindrops in the convective core, ice scattering at $85 \mathrm{GHz}$ is also sensitive to relatively small precipitation-sized ice (few hundred microns) (Lin and Rossow, 1997; Toracinta et al., 2002). Again, instead of comparing absolute intensity, we focused more 

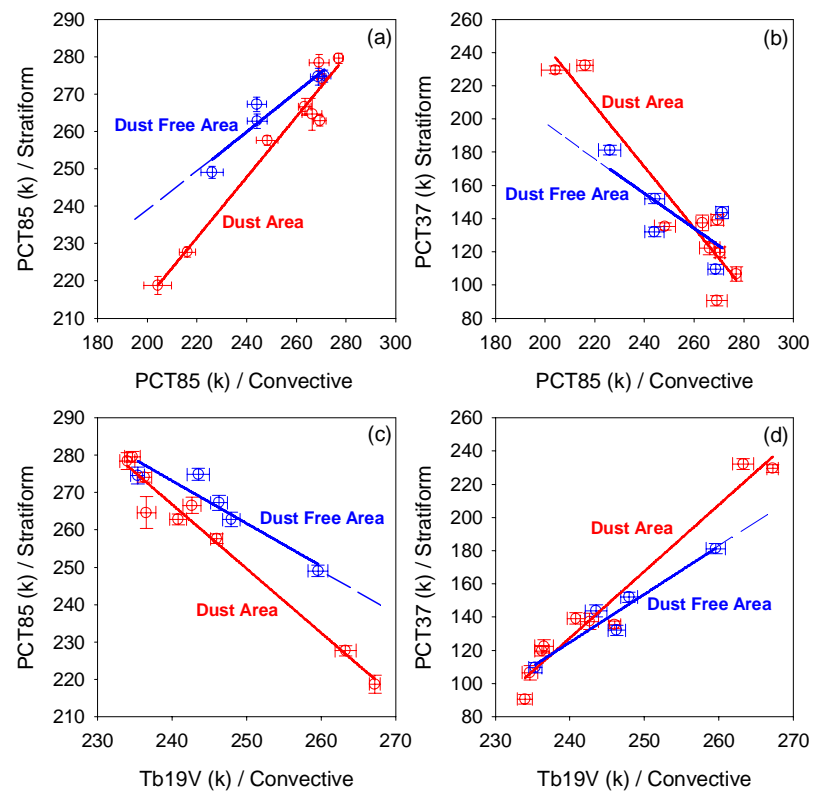

Fig. 4. TRMM TMI observed microwave scattering signals $\quad$ (РCT85=1.82 $\mathrm{Tb}_{85} \mathrm{~V}^{-0.82} \mathrm{~Tb}_{85 \mathrm{H}} ; \quad$ РCT37=2.18 $\mathrm{Tb}_{37} \mathrm{~V}^{-}$ $\left.1.18 \mathrm{~Tb}_{37 \mathrm{H}}\right)$ in the stratiform rains under dust and dust-free conditions for given PCT85 (a, b) and $\operatorname{Tb} 19$ (c, d) in their associated convective cells.

on the relationship of ice scattering signals between stratiform rains and convective rains. As shown in Fig. 4, the mean polarization-corrected temperatures (PCTs) at $85 \mathrm{GHz}$ (PCT85) (Spencer et al., 1989) in the stratiform rain region above segregated convection cells are reduced more severely in the dust sector than in the dust-free sector for a given PCT85 in the convective region. The PCT85 in convective rains is a good indicator of updraft intensity as discussed by Zipser et al. (2006). This suggests that more small ice particles presented in the dust sector for a given convection strength. In the meantime, the PCTs at $37 \mathrm{GHz}$ (PCT37) (Toracinta et al., 2002) in the dust sector are warmer than in the dust-free sector, indicating fewer large precipitating ice particles due to the present of mineral dust. Furthermore, if we used the brightness temperature at $19 \mathrm{GHz}$ (TB19), which is related to cloud column integrated liquid water, in the convective cores as another indicator of the dynamic and thermodynamic conditions of the convection, under dusty conditions the PCT 85 and PCT37 are also colder and warmer than under dust-free conditions for a given TB19, respectively. Passive microwave measurements further corroborate the possibility that mineral dusts interact with clouds microphysically and result in more small sized but less large sized hydrometeors in the stratiform rain region than its pristine counterpart.

Furthermore, a closer look at the impact of mineral dust on the growth of precipitating ice particles below the rain top reveals even more distinct behavior in the convective and
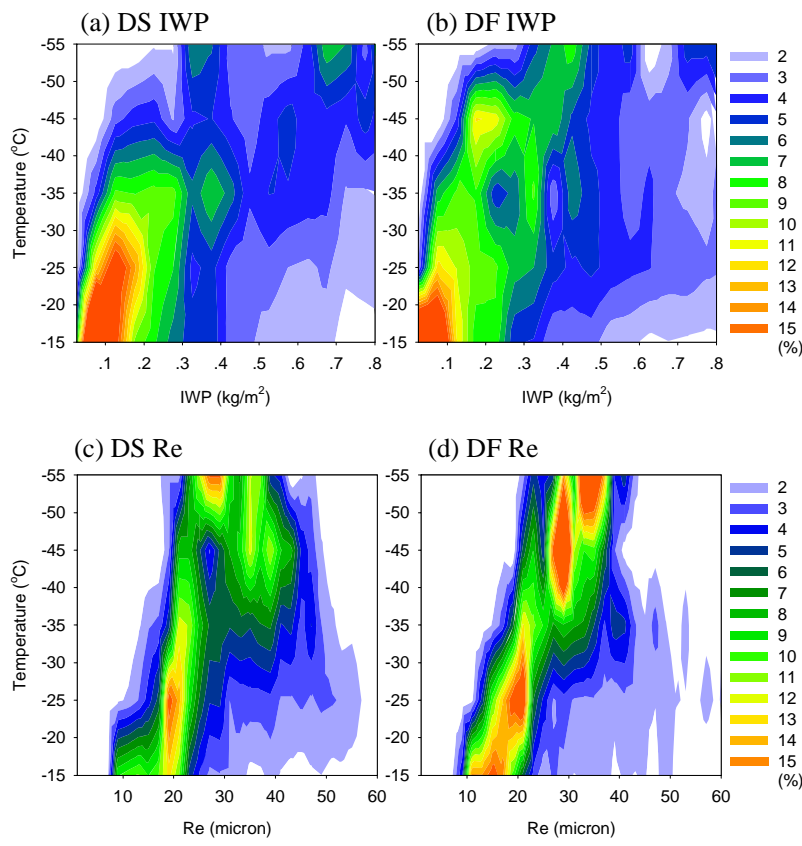

(d) DF Re

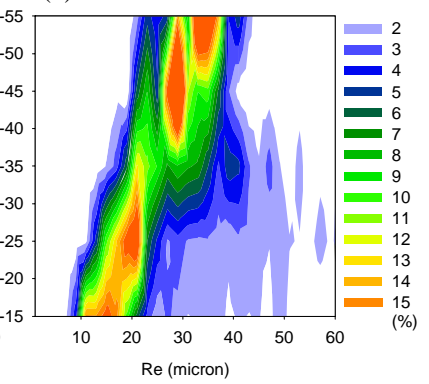

Fig. 5. TRMM VIRS retrieved contoured occur frequency (\%) by cloud top temperature diagrams of ice water path (IWP, $\mathrm{g} / \mathrm{m}^{2}$ ) and ice particle effective ice radius $(\mathrm{Re}, \mu \mathrm{m})$ in non-raining clouds under dust and dust-free conditions.

stratiform regions. In the convective region ice particles in the dust-free sector were larger than those in the dust sector although there was an abundant supply of precipitable water for hydrometeor growth in both sectors. This interpretation follows from the similarity of the slopes of the vertical profile of the maximum occurrence reflectivity of the CFAD above $5 \mathrm{~km}$ (Fig. 2), and the larger median reflectivities in the dustfree sector as compared to the dust sector. In the stratiform precipitation region, an abundance of small ice particles in the dust sector competed for available water vapor through vapor deposition growth, and thus limiting their growth rate. Thus, the slope of vertical profile of median reflectivity between 5 and $7 \mathrm{~km}$ was $2.37 \pm 0.39(\mathrm{dBZ} / \mathrm{km})$ in the dusty stratiform sector, and smaller than $4.32 \pm 0.51(\mathrm{dBZ} / \mathrm{km})$ in the dust-free sector. Below the freezing level, the maximum occurrence of the reflectivity tended to decrease toward the surface, due to evaporation of precipitation hydrometeors, collapse of large precipitation particles, and reduction of fall speed. Overall, mineral dust appears to suppress heavy precipitation and enhance light surface precipitation in both convective and stratiform regions near the surface.

Observed changes in precipitation as consequences of mineral dust indirect effect should also have its signatures in associated non-rain clouds. We retrieved cloud ice water path (IWP) and cloud effective radius from the TRMM VIRS (Visible and Infrared Scanner) observations. The contoured occurrance frequency by cloud top temperature diagrams of IWP (Fig. 5) show there are much more cloud ice 
(much smaller ice particles than precipitating ice) present in the dust sector than in the dust-free sector for cloud top temperatures above $-40^{\circ} \mathrm{C}$. There is another peak in the dustfree sector at cloud top temperatures around $-45^{\circ} \mathrm{C}$. The contoured frequency by cloud top temperature diagrams of ice particle effective radius, on the other hand, illustrates that a strong temperature dependence of ice particle size in the dust-free sector in contrast to a near constant ice particle size above $-40^{\circ} \mathrm{C}$ and a big change in ice particle size below $-40^{\circ} \mathrm{C}$. Combining ice cloud IWP and effective radius information, it is plausible that more ice nuclei (IN) introduced by large concentrations of mineral dusts produce more ice particles at warmer temperatures. Additionally, water vapor depletion as a consequence of mineral dust heterogeneous nucleation may reduce the peak supersaturation at higher altitudes, which limits the onset of the homogeneous nucleation process. Evidence of abundant cloud ice particles in the dust sector, particularly at attitudes where heterogeneous nucleation process of mineral dust prevails, further supports our observed changes of precipitation and provides a complete and consistent picture of mineral dust-cloud-precipitation interaction.

From the above analyses, it is reasonable to hypothesize that observed evidences, at least in this case, are the consequence of mineral dust indirect impact on precipitation internal structures. Mineral dust as effective ice nuclei increases the overall concentration of ice hydrometeors through heterogeneous nucleation (DeMott et al., 2003; Sassen et al., 2003). Nucleated particles that are lofted to higher levels of the cloud through convective updrafts experience slow growth through vapor deposition in the dusty environment due to competition among the dust-enhanced nuclei concentration. Note that their presence, confirmed by passive microwave and visible/infrared sensors, cannot be detected by the PR in the convective rains because their reflectivity is below the $P R$ size detection threshold (about $17 \mathrm{dBz}$ ). When advected into in the stratiform region with the convective outflows, sufficient time has elapsed to allow the growth of ice crystals to sizes detectable by the PR as evident by the high reflectivity observed in the stratiform dust region. Conversely, in the dust-free sector nuclei concentration is lower and the growth to PR detectable sizes is more rapid in the convective region, resulting in observable higher PR reflectivity. The contrast features of stratiform/convective rain intensity between the dust and dust-free sectors may also suggest that all convective cells in the dust sector are transformed to stratiform rains relatively earlier than their counterparts in the dust-free sector. It implies that mineral dust has a significant impact on the cloud evolution. We believe that both pathways, microphysical and storm evolution, are plausible explanations, and possibly our observed features can be better explained by the combined effect of both pathways. The combined effect is consistent with a conceptual model proposed by Rosenfeld et al. (2008). Of course, the observation here only shows a supporting evidence and cannot provide a conclusive judg-
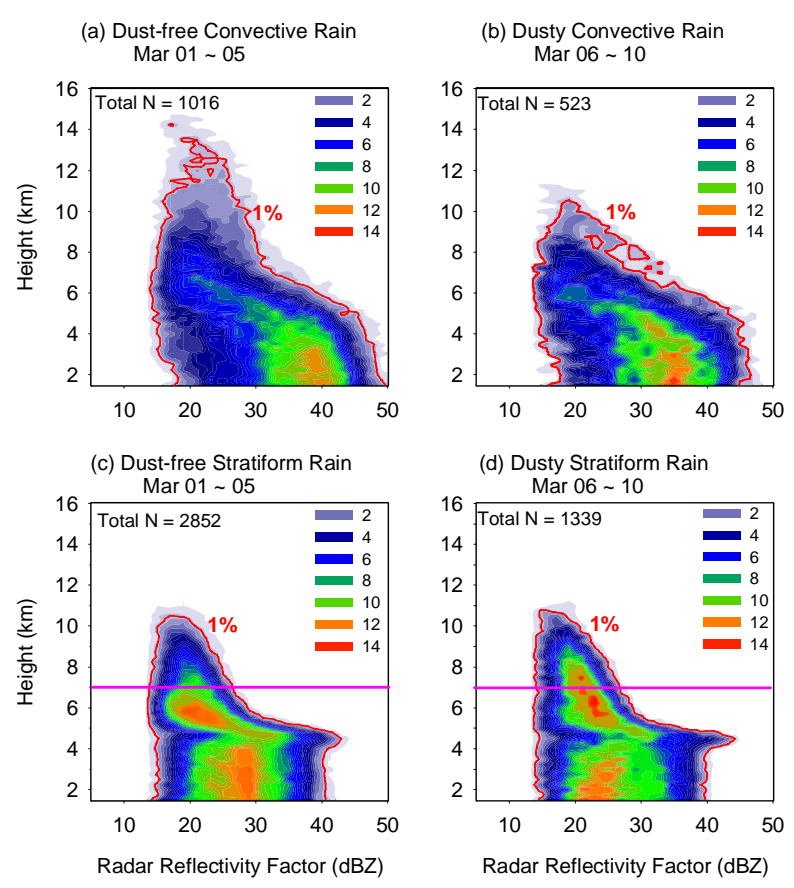

Fig. 6. Contoured frequency by altitude diagrams (CFADs) of PR attenuation corrected reflectivity for both convective and stratiform precipitation regions for dusty period (6-10 March 2004) and dustfree period (1-5 March 2004).

ment owing to the lack of continuous observations.

While a case study shines light on detailed physical processes, a statistical investigation will provide a more solid understanding and confirmation. We conducted a very limited ten-day (1-10 March) statistical study during this dust storm event. We selected a fixed area of $0^{\circ}$ to $4^{\circ} \mathrm{N}$ and $10^{\circ} \mathrm{W}$ to $5^{\circ} \mathrm{E}$. Based on time series of MODIS retrieved aerosol optical depth (Fig. 1f), the period of 1-5 March is defined as the dust-free period, while the period of 6-10 March as the dust-laden period. The CFADs of PR reflectivity during both periods are shown in Fig. 6. Although the dust samples during the dust period only increase $\sim 50 \%$ from the case study, all dust-free samples in the dust-free period are different from those samples in the case study. Nonetheless, the mean intensity of convective rains in the dust-laden period is weaker than that in the dust-fee period, while the mean intensity of stratiform rains above $7 \mathrm{~km}$ is relatively stronger in the dustladen period. These results are consistent with the case study.

\section{Conclusions}

Cloud systems are primarily controlled by large-scale dynamics and thermodynamics and modulated by microphysical processes. The impact of the latter process is extremely uncertain but can be quite profound. In this study we used multi-platform and multi-sensor observations to investigate 
the impact of mineral dust on precipitation internal structures and microphysical interaction of mineral dust-cloudprecipitation. Specifically, we focused on precipitation in a deep convection cloud system over the eastern Atlantic Ocean that was partly influenced by a dust layer. Observed reflectivities from the PR in the stratiform rain region of the dust sector, with slightly weaker convection as compared to the dust-free sector, were higher than in the dust-free sector at altitudes above $8 \mathrm{~km}$. In contrast, the convective region of the dust sector has less frequent occurrence of high reflectivity than in the dust-free sector. Combining with the hydrometeor size information inferred from microwave brightness temperatures of the TMI, it suggests that there were more small sized hydrometeors but less large sized hydrometeors in the stratiform rain region due to the influence of mineral dust than its pristine counterpart. Evidence of abundant cloud ice particles in the dust sector from the VIRS, particularly at altitudes where the heterogeneous nucleation process of mineral dust prevails, further corroborates observed changes of precipitation. All evidences from the combined passive microwave, visible and infrared measurements with active PR measurements and from different entities of the MCS system provide a complete and consistent picture of the mineral dust-cloud-precipitation interaction. This is indicative of enhanced cloud condensation and ice nuclei production from dust aerosol transported by strong convective updraft. Some ice particles grown under the dust conditions are carried to the upper levels of the cloud by the strong convective updraft and contribute to convective precipitation. Other ice nuclei flowed into the neighboring stratiform region and slowly settled downward in the upper layer of the cloud system until reaching the melting level. There were more ice particles in the dust sector. These particles competed for available moisture, limiting their growth. More importantly, two sensitivity analyses further ruled out dynamics as the cause of the observed precipitation difference between the dust and dustfree sectors. The consequences of microphysical effects of the dust aerosols were to shift the precipitation size spectrum from heavy precipitation to light precipitation.

Since our study is based on one dust event and only utilized satellite remote sensing datasets, more robustly statistical study and detailed cloud model simulation are warranted to further understand the microphysical effects of the dust aerosols on clouds and precipitation as well as cloud dynamic impacts on the microphysical processes. Furthermore, the microphysical processes of dust-cloud interaction impact cloud vertical structures and water phase changes, which will alter the vertical gradient of heating profiles in both convective and stratiform regions. Potential vorticity in the tropics is directly proportional to the local vertical gradient in the heating profile (Haynes and McIntyre, 1987; Mapes and Houze, 1995). Such vorticity will further influence the largescale dynamics (Wu and Sarachik, 2000). The actual dynamic feedback to the observed mineral dust indirect effects remains to be evaluated.
Acknowledgements. We thanks for EUMETSAT to provide Meteosat- 8 data and associated image processing tools, and for NASA to provide TRMM Orbit Viewer. This research was supported by the Office of Science (BER), US Department of Energy, Grant DE-FG02-03ER63531, by the NOAA Educational Partnership Program with Minority Serving Institutions (EPP/MSI) under cooperative agreements NA17AE1625 and NA17AE1623, and by NASA Grant NNL06AA00G.

Edited by: U. Lohmann

\section{References}

Andreae, M. O., Rosenfield, D., Artaxo, P., Costa, A. A., Frank, G. P., Longo, K. M., and Silva-Dias, M. A. F.: Smoking rain clouds over the Amazon, Science, 303, 1337-1342, 2004.

Awaka, J. T., Iguchi, K. H, and K. Okamoto: Rain type classification algorithm for TRMM precip-itation radar, Proceedings of the IEEE 1997 International Geoscience and Remote Sensing Symposium, Singapore, 1636-1638, 1997.

DeMott, P. J., Sassen, K., Poellot, M. R., Baumgardner, D., Rogers, D. C., Brooks, S. D., Prenni, A. J., and Kreidenweis, S. M.: African dust aerosols as atmospheric ice nuclei, Geophys. Res. Lett., 30, 1732-1735, 2003.

Gamache, J. F. and Houze Jr., R. A.: Water budget of a mesoscale convective system in the tropics, J. Atmos. Sci., 40, 1835-1850, 1983.

Haynes, P. H. and McIntyre, M. E.: On the evolution of vorticity and potential vorticity in the presence of diabatic heating and frictional or other forces, J. Atmos. Sci., 44, 828-841, 1987.

Houze, R. A.: Stratiform precipitation in regions of convection: A meteorological paradox?, B. Am. Meteorol. Soc., 78, 21792195, 1997.

Iguchi, T., Kozu, T., Meneghini, R., Awaka, J., and Okamoto, K. I.: Rain-Profiling Algorithm for the TRMM Precipitation Radar, J. Appl. Meteorol., 39, 2038-2052, 2000.

Lin, B. and Rossow, W. B.: Precipitation water path and rainfall rate estimates over oceans using Special Sensor Microwave Imager and International Satellite Cloud Climatology Project data, J. Geophys. Res., 102, 9359-9374, 1997.

Mapes, B. E. and Houze, R. A.: Diabatic divergence profiles in Western Pacific Mesoscale convective systems, J. Atmos. Sci., 52, 1807-1828, 1995.

Morris, V., Clemente-Colon, P., Nalli, N. R., Joseph, E., Armstrong, R. A., Detres, Y., Goldberg, M. D., Minnett, P. J., and Lumpkin, R.: Measuring Trans-Atlantic Aerosol Transport from Africa, EOS, Transactions, AGU, 87, 565-571, 2006.

Nalli, N. R., Clemente-Colon, P., Morris, V., et al.: Profile observations of the Saharan air layer during AEROSE 2004, Geophys. Res. Lett., 32, L05815, doi:10.1029/2004GL022028, 2005.

Nesbitt, S. W. and Cecil, D. J.: A census of precipitation features in the Tropics using TRMM: Radar,ice scattering, and ice observations, J. Climate, 13, 4087-4106, 2000.

Rosenfeld, D., Lohmann, U., Raga, G. B., O’Dowd, C. D., Kulmala, M., Fuzzi, S., Reissell, A., and Andreae, M. O.: Flood or Drought: How Do Aerosols Affect Precipitation?, Science, 321, 1309-1313, 2008.

Rosenfeld, D., Rudich, Y., and Lahav, R.: Desert dust suppressing precipitation: A possible desertification feedback loop, Proceed- 
ings of the National Academy of Sciences of the United States of America, 98, 5975-5980, 2001.

Sassen, K., Demott, P. J., Prospero, J. M., and Poellet, M. R.: Saharan Dust storms and indirect aerosol effects on clouds: CRYSTAL-FACE Results, Geophys. Res. Lett., 30, 1633-1636, 2003.

Spencer, R. W., Goodman, H. M., and Hood, R. E.: Precipitation retrieval over land and ocean with the SSM/I: Identification and characteristics of the scattering signal, J. Atmos. Ocean. Tech., 6, 254-273, 1989.

Steiner, M., Houze Jr., R. A., and Yuter, S. E.: Climatological characterization of three-dimensional storm structure from operational radar and rain gauge data, J. Appl. Meteorol., 34, 19782007, 1995.

Teller, A. and Levin, Z.: The effects of aerosols on precipitation and dimensions of subtropical clouds: a sensitivity study using a numerical cloud model, Atmos. Chem. Phys., 6, 67-80, 2006, http://www.atmos-chem-phys.net/6/67/2006/.

Toracinta, E. R., Cecil, D. J., Zipser, E. J., and Nesbitt, S. W.: Radar, passive microwave and lightning characteristics of precipitating systems in the tropics, Mon. Weather Rev., 130, 802-824, 2002. van den Heever, S. C., Carrio, G. G., Cotton, W. R., DeMott, P. J., and Prenni, A. J.: Impacts of Nucleating Aerosol on Florida Storms. Part I: Mesoscale Simulations, J. Atmos. Sci., 63, 17521775,2006
Vivekanandan, J., Turk, J., Stephens, G. J., and Bringi, V. N.: Microwave radiative transfer studies using combined multiparameter radar and radiometer measurements during COHMEX, J. Appl. Meteorol., 29, 561-585, 1990.

Wilheit, T. T., Chang, A. T. C., King, J. L., Rodgers, E. B., Nieman, R. A., Krupp, B. M., Milman, A. S., Stratigos, J. S., and Siddalingaiah, H.: Microwave Radiometric Observations Near 19.35, 92 and $183 \mathrm{GHz}$ of Precipitation in Tropical Storm Cora, J. Appl. Meteorol., 21, 1137-1145, 1982.

Wu, Z. and Sarachik, E. S.: Vertical Structure of Convective Heating and the Three-dimensional Structure of the Forced Circulation on an Equatorial Beta Plane, J. Atmos. Sci., 57, 2169-2187, 2000.

Yuter, S. E. and Houze, R. A.: Three dimensional knematic and microphysical evolution of Florida cumulonimbus, Part II: Frequency distribution of vertical velocity, reflectivity, and differential reflectiveity, Mon. Weather Rev., 123, 1941-1963, 1995.

Zipser, E. J. and Lutz, K.: The vertical profile of radar reflectivity of convective cells: A strong indicator of storm intensity and lightning probability?, Mon. Weather Rev., 122, 1751-1759,1994.

Zipser, E. J., Cecil, D. J., Liu, C., Nesbitt, S. W., and Yorty, D. P.: Where are the most intense thunderstorms on earth?, B. Am. Meteorol. Soc., 87, 1057-1071 , 2006. 